\title{
GENERACIONES Y JUVENTUD: UNA RELECTURA DESDE MANNHEIM Y ORTEGA Y GASSET
}

\author{
FELIPE GHIARDO*
}

\section{Presentación}

CADA VEZ QUE VISITO mi ciudad me llama la atención lo mucho que ha cambiado y crecido en tamaño y cantidad de habitantes. En un período de más menos catorce años, mucho de lo que era viñas y campos fue sembrado con villas y poblaciones. Las antiguas casas del centro, hasta hace poco residencias familiares, hoy albergan oficinas de todo tipo. El comercio también se ha transformado: hay tiendas que ya no existen y otras antes inexistentes; las farmacias más antiguas cerraron y las grandes cadenas coparon los mercados; hace cerca de un año inauguraron algo parecido a un mall y hace poco menos llegó un supermercado Líder. Con estos nuevos elementos, cambió el paisaje de la urbe y con él cambiaron también algunos de los aspectos más simples de la vida misma. De hecho, los remedios o la mercadería ya no se compran donde antes, en la farmacia del boticario conocido o en el supermercado tradicional. Tampoco los lugares de encuentro son los mismos. Muchos ya dejaron de serlo e incluso algunos desaparecieron físicamente. Ahora todos van al mall, esa gran galería comercial.

De todos modos, la presencia de estas novedades no lo ha cambiado todo. Todavía hay cosas que se repiten, que permanecen como

* Licenciado en Sociología, CIDPA Viña del Mar. E-Mail: felipe@cidpa.cl. 
parte del cotidiano, formando parte de la vida en la urbe. Esa sensación me queda cuando en el centro de la ciudad y todavía en la misma esquina, se ve a los muchachos esperar que las muchachas salgan de clases. Ahí se reúnen, conversan, se seducen, y repiten esta especie de «rito» juvenil. Igual que antes. Pero hay algo que lo hace distinto, y es que esos jóvenes no son ni pueden ser los mismos individuos de antes. Éstos ya no están ahí, están en otra parte, haciendo otras cosas o en otra etapa de la vida. Una idea sobre esto me la dio el hermano gemelo de un compañero de colegio cuando nos encontramos de casualidad caminando en la misma dirección. Como llevábamos tiempo sin vernos, fue inevitable que nos contáramos lo que ha pasado con nuestras vidas. Así supe que hacía un par de años había sido padre, que había tenido que abandonar sus estudios por problemas de dinero y que lo más al alcance que tuvo fue dedicarse a chofer de colectivos. Me contó también que su hermano — mi compañero— se había titulado de periodista, que no había conseguido trabajo en su profesión, que por eso se había dedicado a vender computadoras y que así estaba ganando buen dinero. El problema era que justo en ese momento le habían llegado los papeles con la cobranza del crédito universitario. Le dije que ya sabía algo de eso, que su propio hermano me lo había contado en una reunión de compañeros que habíamos hecho algunos días antes para celebrar nuestros diez años de egreso. Sin que preguntara, le conté que ahí pude conversar con varios ex-compañeros que no veía hacía tiempo, que la mayoría había estudiado alguna ingeniería, que ya estaban casi todos recibidos y trabajando y que incluso algunos ocupaban puestos importantes en empresas de la capital. En eso me comentó que si iba al Líder y me acercaba a la «sección carnes», podría ver que el carnicero era un amigo en común que hasta hace pocos años vivía en nuestra misma calle, que posiblemente también me topara con otro antiguo conocido que trabajaba en la «sección de aseo» y con una exnovia suya que estaba de cajera.

No recuerdo en qué momento, ni por qué razón, nos pusimos a comentar no me acuerdo qué tema de la contingencia. Como toda conversación, partimos en un tema y luego planeamos por otros. Hablamos sobre el trabajo, la política, la sociedad, el futuro, la muerte y otras cosas de la vida. Lo curioso fue que mientras la conversación avanzaba, se me hizo evidente que nuestras opiniones apuntaban en direcciones opuestas. Pensándolo bien, no sólo apuntaban, sino que partían de supuestos diferentes, eran formas distintas de ver las cosas. 
En eso terminó su viaje y nuestra conversación. Caminando solo, me descubrí de pronto pensando en la gente de mi edad. Como dijera alguna vez Nietzche, el pensamiento fluye mientras se camina y no sentado en un escritorio. Entonces decidí que lo que me quedaba de camino lo dedicaría a fijarme en toda persona que tuviera, poco más o menos, los mismos años que yo. De los que pude ver me acuerdo, por ejemplo, del que manejaba un triciclo con verduras, del que cuidaba los autos en el estacionamiento de la feria, de la joven que iba vestida con uniforme de secretaria y de la que pedía limosna con un pequeño en brazos. Quienes atendían las multitiendas, hombres y mujeres, también eran casi todos de mi edad, igual que un ejecutivo de esos modernos que vi saliendo del banco y que el carabinero que vigilaba el lugar.

Una lista como ésta es a todas luces limitada, pero cualquiera entenderá que era imposible verlos a todos y a un mismo tiempo. La visión humana no es panóptica y su alcance es finito, pero eso no significa que sea un obstáculo para sacar ciertas ideas y formarse una visión sobre un asunto. El asunto es que bastaba con observar para darse cuenta de cuán distinta venía siendo la vida para unos y otros, cuán dispares las suertes, las trayectorias. Unos abogados, otros taxistas; unos feriantes, otras secretarias. Personas de edades similares ocupadas en actividades tan diferentes, desde las más lucrativas y de mayor estatus, hasta las menos valoradas y de vida más precaria. Diferentes realidades, diferentes formas de enfrentarlas y desiguales condiciones para hacerlo. Pero también, como me quedara claro hace un momento, diferentes formas de pensar, diferentes opiniones sobre temas comunes, sobre la sociedad y los aspectos profundos de la existencia.

Después de todo esto, entendí que este paseo por la ciudad había cristalizado un interés por el tema de lo generacional. Bueno sería, me dije, que el de las generaciones fuera tema para un trabajo sobre temáticas juveniles. Que yo sepa, ha estado algo postergado en la discusión y en la producción de conocimiento sobre este campo y, sin embargo, puede ser una entrada útil para su comprensión. Por eso en lo que sigue trataremos de sintetizar algunos puntos que pueden ser importantes para entender la discusión sobre el tema, daremos una vuelta a los distintos significados que se le han dado al término generación y veremos los alcances que cada uno tiene para la investigación social. Posteriormente, revisaremos algunas interpretaciones del fenómeno generacional como problemática social e histórica, a ver si con todo esto podemos aclarar el término y discutir sobre sus alcances, utilidades y límites pensando en el análisis y estudio de temáticas juveniles. 


\section{SOBRE LAS GENERACIONES}

Si hablamos de generaciones es porque de alguna manera reconocemos que «hay algo» (un fenómeno) que necesitamos representar. Como lo hacemos por medio de las palabras, empezar revisando su semántica puede ser una buena entrada para manejar una imagen de la «parte de realidad» de que se trata. Lo primero entonces será encontrar la etimología de la palabra y revisar sus significados. Para eso lo más a mano son las definiciones que entregan enciclopedias y diccionarios. Según estas fuentes, el término generación viene del latín generatio y señala la acción de generar, de producir. En cuanto a sus usos, lo primero que encontramos nos remite a un fenómeno de tipo biológico. Aquí el término generación comprende los distintos tipos de reproducción adoptadas por la vida orgánica. Generación es la generación de vida: la fecundación y procreación; y las generaciones, las distintas modalidades en que se cumple esta función: generación espontánea, generación sexuada.

Por básica que parezca, esta dimensión es fundamental para entender el fenómeno de las generaciones. Sin reproducción es imposible pensar en una «sucesión de descendientes en línea recta», que es el segundo significado que encontramos de la palabra. La producción de descendencia pasa necesariamente por la generación de nuevos miembros de una especie, cualquiera ella sea. Si lo trasladamos al mundo de lo humano, las generaciones serían la cadena hijo-padre-abuelo, o de manera gráfica, los distintos niveles y ramas de un árbol genealógico. En estos términos, la palabra sirve para designar tanto a los antepasados como a los descendientes; es decir, señala tanto al pasado como al presente y el futuro.

Con la introducción de este componente relacional, la generación deja de ser solamente una acción (generar) y una función (reproducción); ahora comprende también lo que ellas producen: una cadena de filiaciones, que es también una cadena de relaciones: las relaciones de parentesco. Cuando el término incluye relaciones permanentes entre sujetos, el tema de las generaciones se vuelve un fenómeno humanosocial de la mayor importancia. En efecto, las relaciones entre «progenitores» y «sucesores», porque son inevitables, han sido siempre un elemento básico en la definición de cualquier cultura. A partir de ellas, por ejemplo, las comunidades han dividido el trabajo —labores dife- 
renciales para padres e hijos-y elaborado las normas más elementales -tabúes que prohiben el incesto en la relación madre/hijo, por ejemplo- - Además, el carácter de estas relaciones es determinante para la estructuración de las sociedades. En primer lugar, porque en base a esta relación se definen roles y estatus diferenciados según la posición que se ocupe en la estructura de edades. Como señala Duarte «En cada cultura y en cada contexto específico, las formas de relaciones que se van estableciendo entre los grupos sociales [...], están caracterizados por esta condición de poder y control que los mayores poseen respecto de los menores y cómo éstos, de una u otra forma, reaccionan resistiéndose a la situación, o bien amoldándose a ella por medio de diversos mecanismos» (Duarte, 2002:98). En segundo lugar, porque las relaciones parentales constituyen un elemento central para entender la estructuración del poder. La herencia, por ejemplo, ha sido el mecanismo o la «institución» que ha asegurado el traspaso de la propiedad (el patrimonio) de padres a hijos, y es un principio clave para entender la forma en que se han reproducido las relaciones de poder entre los grupos sociales. Recuérdese solamente lo importante que era para cualquier «señor» el nacimiento de un hijo varón: sólo este acontecimiento aseguraba la sucesión de la propiedad y el mantenimiento de una determinada posición - de una familia o de un grupo social más amplio- en la estructura social. El mismo principio se cumple en el otro extremo: la condición de vasallaje de un padre se traspasaba a sus hijos, cosa no muy distinta a lo que ocurre hoy con la condición de pobreza.

Puesto en estos términos, el análisis de las generaciones serviría para observar el modo en que los nuevos miembros de una sociedad -0 de un grupo social específico - van ocupando los roles de sus antecesores y reproduciendo las estructuras sociales: cómo los «menores» se convierten en «mayores». Por lo general, la tendencia ha sido asociar el tipo de análisis que resulta de esta forma de entender a las generaciones con sociedades que mantienen estables sus estructuras por largo tiempo: con sociedades «estáticas». De todas maneras, creemos que las sociedades contemporáneas no escapan a este nivel de análisis. Si lo aplicásemos, por ejemplo, sobre las estructuras de poder contemporáneas, nos daríamos fácil cuenta que su composición tiene clara relación con la transmisión intergeneracional de posiciones de privilegio. No en vano se dice que en Chile la clase dirigente es una «familia». ${ }^{1}$

1 En un artículo publicado en la edición del domingo 28 de marzo 2004 en el Diario La Nación, se cuenta la historia de la familia Chadwick, que desde el 
Ahora bien, si incorporamos el siguiente significado de la palabra - generación como «conjunto de todos los vivientes coetáneos» (RAE), esto es, de todos los que tienen la misma edad-, nos damos cuenta que el tema no se agota en este nivel. Por el contrario, con esto se agregan dos nuevos elementos que llevan la idea de las generaciones a un plano de dinámicas sociales que traspasan ampliamente los límites de las relaciones familiares. El primero: que las generaciones forman conjunto; es decir, que cada generación comprende un tipo singular de elementos, que tienen límites y que ambas cosas las diferencian de otros conjuntos. El segundo: que la edad es el criterio que define esos límites.

Que la formación de generaciones pasa por un tema de fechas de nacimiento es quizás la forma más simple y común de entender el asunto. Por lo general, se asume que el solo hecho de haber nacido en un mismo año implica ya la pertenencia a una generación. Sin duda que la forma en que las sociedades institucionalizan a los sujetos influye en la formación de esta imagen: la incorporación de cada nuevo contingente al sistema escolar, por ejemplo, se define en base al año de nacimiento. Sin embargo, por simple que parezca, asumir la validez de esta definición tiene consecuencias teóricas y prácticas importantes. Pensar que una generación es un conjunto etario y que la componen «todos quienes» tienen una misma o similar edad, implica asumir que una generación abarcaría una fracción completa de una sociedad. En palabras de Ortega y Gasset, una generación es como «un nuevo cuerpo social íntegro, con sus minorías selectas y su muchedumbre» (Ortega y Gasset, 1955:15). Decir que es como «un cuerpo social íntegro», significa que cada generación representa una «totalidad social», algo así como una sociedad «en sí misma», que es, a la vez, subconjunto de un conjunto mayor: la sociedad. «Una generación es una variedad humana» (ibídem), nos dice Ortega y Gasset, un conjunto de individuos «del más diverso temple hasta el punto de que, habiendo de vivir los unos juntos a los otros, a fuer [sic] de contemporáneos se sienten a veces como antagonistas» (ibídem). Del más rico

arribo a Chile de sus primeros exponentes, por allá por 1810, hasta nuestros días, es un apellido que se repite en los círculos de dirigentes. Por varias generaciones, miembros de esta familia han pertenecido a la élite empresarial y, sobre todo, política chilena, independientemente del signo. Unidos por la sangre con la familia Piñera, otro «clan» de la política chilena, entre los miembros de las actuales generaciones se cuentan senadores, alcaldes, consejeros de la televisión nacional, mandamases de oficinas antidroga, etc. Para mayor antecedentes; Saleh, 2004. 
al más pobre y de todos los rincones, todos forman parte de un mismo grupo, de una misma generación.

Esta noción de las generaciones está contenida en las fórmulas más simples de incorporar el tema a la investigación social. En este campo se suele operar desde una imagen de sociedades estructuradas y, por tanto, divisibles por un criterio etario. De hecho, ése es uno de sus procedimientos más comunes: el manejo de cohortes y el uso de la edad como variable-factor para analizar a las poblaciones. Ejemplos hay varios. Los censos generales de población codifican buena parte de sus datos en términos de quinquenios de edad: de 15 a 19, de 20 a 24 , etc. De cada conjunto se hace una «radiografía», se describe su estructura y su situación de momento. De similar modo proceden la mayoría de los estudios sociales. Por poner un ejemplo, un sondeo de opinión que realizó la Fundación Chile 21 para medir la disposición de la población chilena a legislar sobre el divorcio, dividió su universo en tres tramos etarios: 18 a 29, 30 a 42, y «43 años y más». El mismo procedimiento se utilizó para un estudio que realizaron el Programa de Naciones Unidas para el Desarrollo (PNUD) y el Instituto Nacional de la Juventud (INJUV): la población se dividió en las cohortes de 18 a 29, 30 a 34, 35 a 44, 45 a 54, y «55 y más».

En cierta medida, la extendida aplicación de este procedimiento se debe a una especie de «convención disciplinaria». De todos modos, si por un lado estos procedimientos facilitan el diseño de las muestras y el análisis de los datos, eso no significa que su aplicación sea neutra, que no produzca efectos. Para eso basta notar que las cohortes que se identificaron para uno y otro estudio son diferentes tanto en la cantidad como en la extensión de los conjuntos: si en ambos casos la primera cohorte es la misma -18 a 29 años-, las siguientes tienen variaciones importantes, y eso a pesar de que ambos ejemplos consideran la misma población-universo: el conjunto total de la población.

Este solo hecho tiene alcances importantes para los estudios de juventud, pues nos pone ante un dilema obligado en la discusión sobre esta temática: si se puede o no hablar de y analizar a «la juventud» como un grupo etario. En estos casos, «la juventud» aparece como una cohorte: es el conjunto de la población que se encuentra entre los 15 y los 29 años. Con esto, la juventud sería un tramo de edad, y al mismo tiempo, una «etapa en la vida» bien definido. El problema es que los límites de lo que se entiende por «la juventud» han demostrado ser históricamente variables. Hoy parece haber consenso en que esta «etapa» se va al pasar a la treintena, pero hasta hace poco se asumía que se 
iba antes, a los 24. En esto el factor generacional es importante, pues en buena medida la extensión de la juventud como tramo estadísticodemográfico responde a la tendencia de las y los jóvenes a prolongar su período de «dependencia» familiar. Además, no podemos perder de vista que, desde hace un tiempo y sobre todo por la influencia de imágenes que difunde la publicidad, la juventud se ha convertido en un símbolo, en una especie de «estado de ánimo» psíquico y corporal que se representa en signos y prácticas que van más allá de tener o no una edad específica. De hecho, como le pasó hace algunos días a un amigo treinteañero cuando supo que la juventud terminaba a los 29, es probable que estadísticamente se deje de ser joven, pero no que se deje de sentir que se es joven.

Ahora bien, si en la actualidad pareciera haber consenso sobre la edad de término de la juventud, parece no ocurrir lo mismo con la edad en que comienza. Mientras el sondeo de opinión y el estudio del PNUD marcan su inicio en los 18 años — con la mayoría de edad-, en la Tercera Encuesta Nacional de Juventud, por ejemplo, termina a los 29, pero comienza tres años antes: a los 15. La diferencia no es menor, pues si en el primer caso la juventud se inicia con la mayoría de edad, en el segundo parte en la «adolescencia». ${ }^{2}$ Incluso más. Hoy en día la institucionalidad de juventud está interesada en evaluar la posibilidad de incluir como parte de su grupo objetivo a la población entre los 11 y 14 años.

Más allá de los límites precisos de la juventud, si las generaciones son sólo cohortes, entonces habría que aceptar que «la juventud» es una generación. Sin embargo, si consideramos que, por ejemplo, en el mismo estudio del PNUD este conjunto - que hasta aquí es un subconjunto del universo "población total»- se divide en subconjuntos menores (18 a 21, 22 a 25, 26 a 29), entonces debemos aceptar que «la juventud» ya no es una, sino varias generaciones.

De todos modos, si se acepta que la juventud no es una generación, sino varias, no quedan del todo claros los criterios que se utilizan para diferenciar una generación de otra. En la Tercera Encuesta Na-

2 Estas diferencias quizás tengan que ver con la ausencia de «ritos» de pasaje que encierren significaciones culturales compartidas. La mayoría de edad es un «rito» impuesto por el Estado: se reconoce al individuo su calidad de «ciudadano»: para votar, para trabajar, para beber, etc. Sin embargo, no implica en propiedad el abandono de la infancia y el inicio de la juventud (ya no de la adultez). En este sentido, es importante indagar sobre los ritos contemporáneos de pasaje, pues sólo teniendo claridad sobre su forma se pueden definir nociones de juventud pertinentes. 
cional de Juventud, se dividió el universo de jóvenes en tres cohortes: 15 a 19, 20 a 24 y 25 a 29. Si las comparamos con las cohortes que definía el estudio del PNUD, podremos observar las diferencias entre las generaciones que identifica uno y otro estudio. Tampoco queda claro el criterio que se utiliza para asignar la amplitud de cada conjunto. En este sentido, y pese a las diferencias entre las cohortes que identifica cada estudio, ambos siguen el mismo procedimiento: definen intervalos de edad con amplitudes constantes, de cinco años en el primer caso, y de cuatro en el segundo.

De estos puntos arranca una cuestión fundamental. Si bien la edad es un dato importante que tiene que considerar cualquier análisis sobre fenómenos sociales, y por cierto, cualquier análisis sobre fenómenos juveniles, conviene preguntarse si divisiones hechas en términos simplemente «ordinales» entregan un criterio suficiente para dar cuenta de la «realidad» que se investiga. Esto es, si las cohortes construidas en base a constantes numéricas definidas en «laboratorio», son socialmente significativas y contienen o no «realidad».

Hasta el momento la noción de generaciones la hemos visto reducida a conjuntos formados a partir de un solo criterio: el etario. Sin embargo, si las ciencias sociales operan construyendo cohortes es porque, más que un simple «dato», la edad permitiría atribuir cualidades que son compartidas por el conjunto de sujetos. Las teorías más básicas de conjuntos los definen como "una colección bien definida de objetos» que comparten ciertas cualidades en base a las cuales se definen los elementos que pertenecen a cada uno. Cada conjunto supone un nivel de homogeneidad interna que implica, al mismo tiempo, heterogeneidad en su relación con otros conjuntos (Grimaldi, 1998:143).

Ésta es la idea que representa el último significado que encontramos del término: generación como el «conjunto de personas que por haber nacido en fechas próximas y recibido educación e influjos culturales y sociales semejantes, se comportan de manera afín o comparable en algunos sentidos» (RAE). Aquí son dos las piezas que se incorporan al puzzle. La primera es que los miembros de una generación se «comportan de manera afín o comparable»; la segunda, que lo hacen porque operan desde los marcos socioculturales que influyen la acción. Cuando ambos elementos se cruzan con el «factor edad», forman conjuntos que se comportan parecido. 
Nuevamente, el informe del PNUD nos sirve para analizar estos enunciados. En él aparecen una serie de indicadores que informan sobre los comportamientos de la población en relación a un conjunto de variables, y en varias o en casi todas, las diferencias entre las cohortes son más o menos marcadas. Por ejemplo, cuando se pregunta por la asistencia a servicios religiosos, la inclinación de las curvas marca una clara diferencia entre los distintos grupos de edad. De ahí, si consideramos que «la juventud, en comparación con los demás grupos etarios, posee los menores niveles de asistencia a servicios religioSOS» (PNUD, 2003:26), y tenemos en cuenta que en ella el informe encuentra la mayor cantidad de «no creyentes», entonces debemos aceptar que la edad efectivamente opera como un factor que explica la diferencia.

Si llevamos esta línea de análisis al campo específico de «la juventud» y observamos el comportamiento de las cohortes que define la Tercera Encuesta Nacional de Juventud, se observa que la tendencia se repite: en materia de sexualidad, consumo de drogas, educación, trabajo, entre otras, cada conjunto etario se comporta de un modo particular y las variaciones en los valores obtenidos siguen la curva de variación de las edades. Por ejemplo, en el año 2000, el 42.1\% de los jóvenes entre 15 y 18 años había tenido relaciones sexuales, niveles que casi son doblados por los jóvenes del siguiente tramo etario (85.2\%) y que no alcanzan ni a la mitad de los del tercer tramo (95.9\%).

Ahora bien, si los datos muestran diferencias entre las distintas cohortes en que se divide a la juventud, varias de ellas son esperables, pues, a nuestro entender, y se quiera o no, tienen mucho que ver con las realidades que van enfrentando los individuos en la medida que transcurre el «tiempo vivido» y se van actuando los roles definidos por la estructura de clases de edad. ${ }^{3}$ Es un hecho que en la medida

3 Clases de edad es un concepto que «nos remite, en un momento del tiempo, a la división que se opera, en el interior de un grupo, entre los sujetos, en función de una edad social: definida por una serie de derechos, privilegios, deberes, formas de actuar... — en suma, por una 'esencia social' - y delimitada por una serie de momentos de transición — que difieren históricamente: matrimonio, servicio militar, primera comunión, certificados de escolaridad - . A su vez, cada grupo social establece una serie de normas de acceso —-más o menos codificadas y ritualizadas en forma de 'ritos de paso' - de una clase de edad a otra. Esta división de clases de edad, por tanto, es variable históricamente: no depende de una serie de 'naturalezas psicológicas’ previas, sino que se construye en el seno de cada grupo social en función de sus condiciones materiales y sociales de existencia y de sus condiciones y estrategias de reproducción social». Martín Criado, 1998:86. 
que pasan los años se van dejando de hacer cosas y se van haciendo otras que hasta hace un tiempo no se hacían. No por nada el informe del PNUD encuentra en la situación de maternidad/paternidad y en el grado de carga de responsabilidad los factores más determinantes al momento de explicar las variaciones entre las distintas formas de enfrentar la vida que expresan los y las jóvenes. ${ }^{4}$

Pero hay otro punto que nos parece importante tener en cuenta. Si bien es cierto que entre las cohortes se observan diferencias de comportamiento, no lo es menos que la misma tendencia se puede observar al interior de cada cohorte. Si el 42.1\% de los jóvenes que tienen entre 15 y 19 años ha tenido relaciones sexuales, significa que el 57.9\% no las ha tenido. Aunque esto ocurra por una condicionante técnica insalvable, que tiene que ver con que buena parte de las preguntas están planteadas en términos de dicotomía —se mide presencia o ausencia—, nos señala un punto importante: que si una cohorte-generación muestra diferencias respecto a las restantes, esto no significa que al interior de cada una de ellas los comportamientos sean de un solo tipo. De ahí que la homogeneidad de una generación sea impensable, por reducida que sea la extensión del criterio temporal usado para definir la pertenencia al conjunto: si son varios años, un mes o incluso un día.

La psicología contemporánea reconoce que el comportamiento es sólo la «cara visible» de una subjetividad, la forma concreta en que se expresa un modo de «ver» las "cosas del mundo». Estos componentes subjetivos que escapan a la descripción de los comportamientos, de alguna manera suelen ser cubiertos recurriendo a los conceptos de «actitud», "percepción», «opinión», conceptos que suelen ser el objetivo a medir para una porción significativa de estudios sociales. Sin ir más lejos, el informe del PNUD trata de explorar en este terreno cuando intenta fotografiar la subjetividad de los jóvenes contemporáneos midiendo, entre otros aspectos, la aceptación a expresiones diversas, la apertura hacia el extranjero o el grado de individualización. En cada una de estas variables los datos se observan a contraluz con los datos

4 «La forma en que los jóvenes ven la vida está influida por sus niveles de carga de responsabilidad, y esta última varía según la edad de los jóvenes. Así pues, la edad va de la mano con una cuota diferente de obligaciones y libertades». PNUD, 2003:40. 
de los demás grupos etarios, y en cada una se demuestran las diferencias de posición entre jóvenes y adultos. Así, por ejemplo, el informe señala que los jóvenes son quienes más apoyan la diversidad de formas de vida y quienes muestran una postura más individualista que la que adoptan sus padres y abuelos (Cfr. PNUD, 2003:30-32).

La Tercera Encuesta Nacional también intenta medir estas disposiciones subjetivas cuando pregunta, por ejemplo, por la «actitud política» de los jóvenes, los niveles de confianza respecto a las distintas instituciones o el nivel de compromiso social que demuestran. Como se puede anticipar, los resultados asignan a cada cohorte un valor particular. ${ }^{5}$ Sin embargo, por lo general las interpretaciones de los datos se hacen en base al valor total de cada variable, que no indica sino la «actitud promedio» de la juventud como conjunto. Así, por ejemplo, en materia de actitud política, los datos obtenidos permitirían constatar la presencia de una «onda juvenil» — como la llaman en el informe de la encuesta - que apunta a no inscribirse en los registros electorales. «En efecto — dice- una mayoría del $61.5 \%$ de los jóvenes no está inscrito en dichos registros», que es de por sí un valor estadístico bastante significativo. El problema es que, como plantea Martín Criado, procedimientos estadísticos de este tipo permiten «construir la opinión media o mayoritaria como la opinión de la 'juventud' — legitima estadísticamente la ilusión de la existencia del grupo-: mediante le encuesta de opinión, el sociólogo transforma 'el 55\% de los jóvenes opina que...’ en 'la juventud opina que...’» (Martín Criado, 2003a:4) y reducen el análisis de las generaciones a un asunto de mayorías.

Puesto en estos términos, el análisis de la juventud correspondería nuevamente al análisis de una generación, pues ella estaría impregnada, como dice Ortega y Gasset, de una «sensibilidad vital», de una «sensación radical ante la vida» que brota espontánea del espíritu de cada individuo. ${ }^{6}$ Para el filósofo español, es esta sensibilidad la esencia de una generación, lo que define el carácter de todos quienes comparten una misma edad. Ella aflora en cada momento, sin importar diferencias ideológicas ni sociales. Por lo demás, si éstas llegasen a aparecer, de seguro se deberán a diferencias de temperamento que son

5 Así, por ejemplo, el año 2000, sólo el 11.1\% de los jóvenes entre 15 y 19 años se encontraba inscrito en los registros electorales; $29.8 \%$ de los que tienen entre 20 y 24, y el 59.4\% de los jóvenes entre 25 y 29 años. Cfr. INJuV, 2002:83.

6 En El tema de nuestro tiempo, Ortega y Gasset desarrolla esta idea y propone que la característica última de una generación, el hilo que une al conjunto de sus miembros, se encuentra en esta «sensibilidad vital». Cfr. Ortega y Gasset, 1955. 
inevitables pero que en modo alguno implica que no se comparta ese sustrato último.

Si bien esta «disposición profunda» de la que habla Ortega y Gasset, por su nivel de abstracción resulta un concepto difícil de captar y medir para las ciencias sociales, hay un momento en el informe del PNUD en que se intenta llegar a un componente subjetivo que se asemeja a esta idea. Ese componente común aparece contenido en una «demanda por comunidad» compartida por el conjunto de la juventud chilena de principios del siglo XXI y que sería la forma en que está cristalizando su búsqueda de sentido. ${ }^{7}$ No obstante, esta demanda surge a partir de que el fenómeno que se constata es su contrario: la fragmentación de sentidos. De hecho, el mismo estudio da cuenta de esta realidad cuando construye una «tipología» para representar los distintos modos de ser joven y de «sentir la vida». ${ }^{8}$ Más allá de los tipos específicos que se identificaron, lo interesante es ver que en ella el factor etario no es el determinante. Tanto o más que la edad, son los factores sociales, demográficos y —en menor medida — de género los que mejor explican las distancias que separan los sentidos que los jóvenes dan a la vida. ${ }^{9}$ En efecto, cada «tipo» que identificaba el informe del PNUD representa el sentir frente a la vida y la sociedad de

7 «La juventud chilena —entendida como un grupo- pareciera compartir una demanda por comunidad. Esa demanda se traduciría en una búsqueda de sentido compartido, el cual podría encontrarse en alguna colectividad (grupos de música, barras bravas, etc.) o bien en alguna forma de solidaridad social (por ejemplo en los trabajos voluntarios). Dicho de otro modo, las diferencias al interior de la juventud dejan planteada la cuestión de su integración». PNUD, 2003:44.

8 Está el joven lúdico, que goza de la vida y no le teme a un futuro porque le parece auspicioso; está el joven utilitarista, que ha tenido tropiezos en el camino, pero aun así tiene expectativas para el futuro; el joven agobiado, a quien el tiempo le ha ido agotando las posibilidades de pasarlo bien y diluyendo las esperanzas para el futuro; y está el joven integracionista, sin muchas oportunidades ni herramientas, pero que confía que algún lugar podrá encontrar en el sistema económico, aunque no sea un trabajo que entregue mucha satisfacción. Cfr. PNUD, 2003:42-43.

9 Datos que demuestren esta realidad encontramos varios. En la Tercera Encuesta Nacional de Juventud, cuando se mide, por ejemplo, la «autopercepción», los resultados señalan que «El nivel socioeconómico determina claras tendencias en la autodefinición juvenil, pues mientras los jóvenes de nivel socioeconómico alto se describen principalmente como sociables (45.8\%), soñadores (37.3\%) e idealistas (34\%); los de sectores medios lo hacen como trabajadores (36.5\%), solidarios (30.9\%) y sólo en tercer lugar como sociables (30.4\%). Por su parte, los de nivel socioeconómico bajo se perciben trabajadores (47.2\%), solidarios (32.7\%) y tranquilos (30.6\%)». INJUV, 2002:94. 
sujetos que viven una realidad social específica. ${ }^{10}$ En este sentido, tiene razón Mannheim cuando plantea que compartir una edad, años más años menos, no basta para formar generación. «La contemporaneidad del nacimiento —nos dice-, de hacerse joven, adulto, viejo, no es constitutiva de la situación común en el espacio social [...] No se puede hablar de una situación de generación idéntica más que en la medida que los que entren simultáneamente en la vida participen potencialmente en acontecimientos y experiencias que crean lazos. Sólo un mismo cuadro de vida histórico-social permite que la situación definida por el nacimiento en el tiempo cronológico se convierta en una cuestión sociológicamente pertinente» (Mannheim, citado en Martín Criado, 1998:80). No es que la edad no importe. Para el sociólogo alemán, el tiempo transcurrido desde el nacimiento es un dato ineludible si se quiere entender las implicancias del fenómeno de las generaciones. Pero si la edad marca el tempo al desarrollo de los cuerpos-mentes individuales, la similitud biológica sería sólo un dato sin mayor relevancia porque ella sola no explica fenómeno sociológico alguno.

Para Mannheim, lo importante no son las generaciones en sí mismas. La aparición de nuevos individuos es un proceso biológico inevitable para la mantención de una especie, pero su constatación no explica por sí solo el significado social de las generaciones en tanto realidad, como define Mannheim a este fenómeno. En su esquema analítico, junto con haber nacido en períodos cercanos, el primer requisito para que puedan aparecer formas de ver, sentir y vivir la vida común a un conjunto de individuos es que compartan una misma situación de generación, que es el punto donde se unen el tiempo histórico y las condiciones sociales e históricas de existencia. Con la idea de situación de generación, Mannheim entrega al análisis una mayor precisión conceptual que le permite salvar el problema que supone poner en equivalencia la coetaneidad con la identidad subjetiva. El asunto hay que llevarlo al plano de las condiciones sociales y culturales en que viven los sujetos, pues son ellas las que en definitiva determinan los modos de experiencia y conciencia posibles. ${ }^{11}$ De una de-

10 Así, los jóvenes lúdicos son hombres principalmente de estratos socioeconómicos medio y medio alto, el utilitarista es de nivel socioeconómico medio y medio bajo, igual que el agobiado y el integracionista. Cfr. PNUD, 2003:40-41.

11 «La situación de clase y la situación de generación (pertenencias a clases de edades vecinas) tienen en común circunscribir, por el hecho de su situación específica en el espacio sociohistórico, a los individuos en un campo de posibles determinado y favorizar así una modo específico de experiencia y de pensa- 
terminada situación de generación, como de una determinada situación de clase, pueden aparecer grupos sociales concretos, formados por una filiación consciente y en base a relaciones permanentes entre sus miembros, que sean portadores de una «visión del mundo» compartida. A ese fenómeno social específico, que Ortega y Gasset define como generación, Mannheim lo llama unidad generacional, que es el punto donde la edad y la vivencia de una misma situación cristalizan en un esquema de ideas y actitudes que interpreta la situación de un conjunto de sujetos. ${ }^{12}$ De ahí que de una misma generación real, de un mismo conjunto de sujetos contemporáneos, puedan aparecer distintas o incluso opuestas unidades generacionales.

Bourdieu comparte esta idea propuesta por Mannheim, que las generaciones no son grupos etarios. Para el sociólogo francés, compartir una edad cronológica es fundamental, pero no es lo que determina la producción de un habitus más o menos común a un conjunto de sujetos. ${ }^{13}$ Este proceso depende más de otros factores, que están en función de la posición que se ocupa en el espacio y el tiempo social. En este sentido, hablar de una generación significa para Bourdieu hablar de los modos en que se «producen» los sujetos, que no son ni pueden ser los mismos para toda la sociedad. Por el contrario, a cada grupo social le corresponde una forma de producción específica, definida por su posi-

miento, un modo específico de intervención en el proceso histórico. Cada situación descarta por tanto un gran número de modos de experiencia, de pensamiento, de maneras de sentir y actuar posibles y restringe el margen de juego de los efectos de individualidad a posibilidades precisas y limitadas». Mannheim, citado en Martín Criado, 1998:81.

12 «Pode-se dizer que os jovens que experienciam os mesmos problemas históricos concretos fazem parte da mesma generação real: enquanto aqueles grupos dentro da mesma generação real, que elaboram o material de suas experiências comuns através de diferentes modos específicos, constituem unidades de generação separadas». Mannheim, 1982:87.

13 «El habitus se define como un sistema de principios generadores de prácticas, apreciaciones y percepciones. Este sistema es incorporado a lo largo de la historia del individuo — su matriz básica se forma en la 'socialización primaria'mediante un proceso de familiarización práctica con uso espacios y prácticas producidos siguiendo los mismos esquemas generativos y en los que se hayan inscritas las divisiones y categorías del mundo social del grupo en el que el individuo se encuentra. El habitus es la 'clase incorporada'. Es el aprendizaje del espacio social y de la posición que se ocupa en él en forma de esquemas prácticos de acción, percepción y apreciación. Este aprendizaje, al ser práctico, no pasa por la conciencia: está incorporado en el pleno sentido de la palabra: hecho cuerpo». Martín Criado, 1998:75-76. 
ción en el sistema de relaciones sociales que, para Bourdieu, es igual al sistema de relaciones de dominación. De ahí, si una generación señala el proceso de producción de los nuevos miembros de un grupo social, significa también que es el modo en que se reproducen los grupos sociales y, con ellos, el sistema de dominación en que se inscribe su existencia.

En el planteamiento de Bourdieu, la clave pasa por la posición que ocupa un grupo en el sistema de distribución de las distintas especies de capital, ${ }^{14}$ que son los que imponen los límites a la formación de un determinado habitus. En este sentido, haber nacido parte de un grupo social — de una clase, por ejemplo - acota las posibilidades de movimientos a las trayectorias vitales de los sujetos y hace que pasen por situaciones comunes. En el caso específico de la juventud se constata esta realidad cuando observamos que cada tipo de capital se encuentra distribuido de manera dispareja. Así, por ejemplo, en relación a lo que ocurre con el manejo de «herramientas de modernización», el informe del PNUD señala que «es importante destacar que la brecha en el uso de las herramientas modernizadoras no sólo se da entre jóvenes y adultos. En esta materia también existen diferencias al interior de la juventud, algo que se hace patente al ver cómo se agrupan los jóvenes a partir de la tenencia o ausencia de las tres herramientas de modernización más básicas: uso de computador, uso de internet y dominio de inglés. $\mathrm{Al}$ analizar estos datos se marca una tendencia que es propia de la sociedad chilena: una muy desigual distribución de los recursos» (PNUD, 2003:14), que como es de esperar está fragmentada principalmente de acuerdo al nivel socioeconómico y al área de residencia. Cosa parecida ocurre con la apropiación de capital en el campo cultural: no toda la juventud cuenta con las mismas oportunidades de acceso a la «cultura». Como señala el mismo informe, «la importancia de este asunto no es menor. Si bien la sociedad en su conjunto tiene un acceso diferenciado a la cultura, en el caso de los jóvenes esa inequidad tiene implicaciones particulares. La desigual distribución de recursos culturales se traduce

14 «El capital es una relación social que define la apropiación diferencial por los sujetos del producto socialmente producido. Marx sólo tuvo en cuenta el capital económico. Bourdieu, en un intento de fundar una economía política generalizada, distingue otras especies de capital —que, como el económico, suponen apropiación diferencial del producto socialmente producido: son relaciones de dominación—: un capital cultural — con subespecies, como el capital lingüístico- - un capital escolar — capital cultural objetivado en forma de títulos escolares-, un capital social —relaciones sociales movilizables para la obtención de recursos—, un capital simbólico — prestigio-...». Martín Criado, 1998:73. 
en un diferencial de recursos para definir y realizar sus proyectos de vida» (PNUD, 2003:28). De ahí se entiende que las distintas situaciones de generación contengan en potencia una visión de mundo: no es lo mismo participar de la sociedad desde dentro que desde sus márgenes.

Si la pertenencia a uno u otro grupo socioeconómico determina situaciones de generación diferentes, lo mismo ocurre con el área de residencia. Las «sensibilidades vitales» que se generan son distintas, porque no es lo mismo nacer, crecer y ser joven en una gran urbe que en un pueblo o sector inmerso en la ruralidad. El informe del PNUD es claro en esto cuando señala que «el nivel de apertura al extranjero de la juventud varía considerablemente en función del lugar desde donde se observa la realidad: mientras el mundo rural presenta las tasas más bajas de apertura al extranjero, los jóvenes santiaguinos manifiestan una mayor cercanía con lo cosmopolita» (PNUD, 2003:17). De ahí, cada situación supone un tipo de experiencia singular y distintivo, que sin duda marca las condiciones en que en uno y otro campo se producen sujetos. Si en el mundo urbano y en el mundo rural este proceso presenta una forma particular, es porque tiene su propia dinámica, su propia historia.

Con todo, queda claro que la edad está lejos de ser el único factor a tener en cuenta si se quiere captar los componentes subjetivos de una generación. La homologación permanente entre los fenómenos generacionales y la variable edad, que ha sido práctica habitual en el campo de la investigación social, no ha hecho sino «naturalizar» las características de los coetáneos y dificultar una comprensión de los fenómenos juveniles que incorpore o incluso que parta desde una perspectiva generacional. Como señala Martín Criado, «la relación simple y unidireccional de esta variable [la edad] con las «variables dependientes» —ideología, voto, «actitudes», etc. — identifica, sin más, la contemporaneidad cronológica — el hecho de pertenecer a la misma cohorte- con la identidad social» (Martín Criado, 2003b:1). Al mismo tiempo, y lo que es importante para los estudios de juventud, la división por edades crea imágenes sobre los tramos etarios - ya se trate de «la juventud» o de las posibles cohortes en que se la suele dividire instala la idea que una edad o un tramo etario corresponde a una «etapa de la vida» de características extensibles a todo individuo, sin reconocer que ellas le vienen del carácter de una generación específica. Es decir, no porque, por ejemplo, quienes hoy tienen entre 15 y 19 años demuestren niveles altos de «individualización», significa que todo aquel que en cualquier tiempo tenga una edad en ese tramo vaya a presentar la misma disposición ante la vida. 


\section{GENERACIONES, TIEMPO Y PROCESO HISTÓRICO}

\section{1}

La noción de generación forma parte de los esquemas con que las distintas culturas y civilizaciones han interpretado la relación entre tiempo y existencia. Cada noción de las generaciones se encuentra en estrecho vínculo con la forma en que cada cultura resuelve el problema del tiempo. Por lo general, las culturas antiguas le dieron la forma de ciclos. En la China antigua, por ejemplo, las generaciones representaban la unidad de medida temporal que articula el tiempo humano y los ciclos naturales. Igual como en la lluvia, las plantas y los animales se descubren ciclos, los seres humanos, como seres naturales, siguen el mismo movimiento. También es cíclica la noción que se manejaba en la antigua Grecia, aunque aquí, más que los ciclos de la naturaleza, la sucesión de generaciones explicaba el curso cíclico de los procesos históricos.

Esta imagen de las generaciones persiste en occidente hasta que la hegemonía de la doctrina cristiana niega el vínculo entre tiempo y existencia. Las generaciones evocan la materialidad de lo humano y la finitud del tiempo, y eso era precisamente lo que se pretendía «superar». Debió pasar un buen tiempo para que esta concepción se trizara y el problema del tiempo histórico retomara su centralidad. Los primeros golpes vinieron desde el Renacimiento y luego toman fuerza con la aceleración de las transformaciones que acompañan a la «modernidad». En la medida que se expande el pensamiento moderno y se aclara el vínculo entre «lo real» y «lo temporal», las generaciones fueron recuperando su relevancia como fenómeno social e histórico. Mediando el siglo XIX, Comte se ancló en ellas para explicar el «progreso» y la «evolución» social, y ya en los albores del siglo XX, el problema de las generaciones es uno de los factores claves para explicar el proceso de cambio histórico. Todo el trabajo teórico sobre las generaciones que en esta época desarrollan Dilthey y otros, y que luego continúa Ortega y Gasset, se enmarca en intentos por construir una Teoría de la Historia. De hecho, si este último toma el tema de las generaciones es precisamente porque ve en ellas una constante, un hecho presente en todo tiempo que puede ser el principio para definir la ley histórica fundamental. ${ }^{15}$

15 «La generación — dice Ortega y Gasset - compromiso dinámico entre masa e individuo, es el concepto más importante de la historia, y, por decirlo así, el gozne sobre el que ésta ejecuta sus movimientos». Ortega y Gasset, 1955:15. 
En las teorías modernas de las generaciones aparece inevitablemente contenida la forma «moderna» de concebir la relación entre «ser y tiempo». Cuando leemos El tema de nuestro tiempo de Ortega y Gasset, nos encontramos con que el tiempo es aquí un factor absoluto: cubre todas las manifestaciones humanas y alcanza a cada individuo viviente. La idea es que la estructura de un período histórico explica la formación de las ideas, las preferencias morales y estéticas de quienes lo viven. Aunque cada período represente una pequeña «porción» en el gran flujo del tiempo, para los contemporáneos es el telón en cuya superficie se inscribe su vida, el mismo que le impone límites a sus modos de sentir, pensar y vivir. Si los marcos socioculturales son importantes para definir a una generación, ellos dependen del tiempo histórico y representan sólo una de las formas en que se expresa. Este es el marco de fondo para una generación, el que define su particular «sensibilidad vital». Como dice Ortega y Gasset, todos quienes nacen en un mismo período de tiempo «vienen al mundo dotados de ciertos caracteres típicos, que les prestan una fisonomía común [...] Unos y otros son hombres de su tiempo, y por mucho que se diferencien se parecen más todavía. El reaccionario y el revolucionario del siglo XIX son mucho más afines entre sí que cualquiera de ellos con cualquiera de nosotros» (Ortega y Gasset, 1955:15-16). Todos sienten la vida de una misma forma históricamente definida; por eso los contemporáneos pueden ser representados en una imagen condensada.

Representar en un «tipos ideales» a quienes viven o vivieron en una época histórica es un procedimiento corriente en varios campos de estudio. Suele ser aplicado, por ejemplo, en el análisis histórico cuando se describe al «Hombre del Renacimiento» o al «Hombre Moderno». También se aplica en el campo de los estudios literarios, que es quizás el que más ha incorporado el fenómeno de las generaciones. La idea de fondo es que en el conjunto de escritores nacidos y formados en un mismo tiempo histórico se puede encontrar un componente subjetivo común que transluce en sus temáticas, sus formas narrativas y sus lenguajes. El haber vivido una misma época les haría "sentir» de un modo característico, tener una actitud compartida ante al mundo y la literatura misma. Incluso, cuando los estudiosos encuentran el hilo que los une o el hito histórico que los marca, les bautizan y ponen nombre: Generación del 38, Generación del Boom, etc. Así, por ejemplo, en el prólogo a su Antología del cuento chileno, Enrique Lafourcade escribe: «La voz Generación del 38, de uso corriente en Chile, intenta designar a diversos novelistas, ensayistas, poetas y cuentistas 
surgidos con el advenimiento del Frente Popular en nuestro país, y la Guerra Civil Española» (Lafourcade, 1985:25). Estos procesos históricos son los faros que iluminan la obra de los autores que iniciaron su producción literaria en ese tiempo. Desde ahí brotan sus temáticas y se formulan sus intenciones literarias. "¿Qué se proponen? — se pregunta Lafourcade- Acentuar el realismo. Transformar la literatura en un arma. Actuar como intelectuales en la modificación del mundo. La protesta, el testimonio, la denuncia, la lucha franca contra el fascismo» (Lafourcade, 1985:26). Lo mismo se aplica luego a la Generación del 50 , formada por escritores que, pese a su heterogeneidad y marcadas diferencias de estilo, tendrían en común «una angustia indefinida que da origen a una rebeldía sin causa ni propósito y que, en el fondo, no es sino reflejo del sentimiento existencialista que aplasta a las nuevas generaciones de Europa y Norteamérica» (Lafourcade, 1985:33).

En el campo de las ciencias sociales, el tiempo es un referente fundamental para cualquier análisis que incorpore comportamientos, actitudes u opiniones. Los estudios que hemos venido utilizando como referencia así lo demuestran. En efecto, si tomamos los indicadores que en cada variable presentan el valor más alto, sea para la población joven total o para una sub-cohorte específica, es posible ir juntando los puntos y definiendo el perfil de «la juventud de hoy». Así tenemos, por ejemplo, que en su mayoría son jóvenes que inician su vida sexual entre los 15 y los 18 años, que están estudiando, que son tolerantes de la diferencia y abiertos al contacto con el mundo (cfr. PNUD, 2003; INJUV, 2002). Cada dato que se agrega, descubre un nuevo rasgo y afina el perfil del sujeto-joven-contemporáneo. No obstante, y se quiera o no, la figura que aparece es parcial, pues se construye en base a los datos de la «mayoría». En ningún momento puede ser más que un «tipo ideal», un acercamiento general, nunca completo. El detalle lo advierte Lafourcade cuando reconoce que «la voz generación está utilizada en tanto arbitrio ordenador, límite o frontera caprichosa para distribuir una realidad más o menos heterogénea» (Lafourcade, 1985:25). El mismo Ortega y Gasset llama la atención sobre los límites que implica identificar a las generaciones en términos sólo etarios cuando reconoce que son «sólo imágenes».

Así como en el campo de la literatura «no es posible hablar de 'una generación' cuando se comparan obras de autores nacidos exactamente el mismo año» porque «la condición de sus obras se diferencia por cuestiones de género, de filiaciones literarias e ideológicas, por contexto de producción y recepción de sus obras, por modos de asu- 
mir la escritura y un proyecto escritural» (Cuadros, 2003), su aplicación al campo de de los estudios sociales no deja de encerrar complicaciones si pensamos que analizar la realidad a partir de «moldes» implica hacer calzar a su estructura la multiplicidad de formas en que se expresan los fenómenos sociales y humanos. Pensando en su aplicación al análisis de las generaciones, quizás el mayor problema sea que esas imágenes van quedando como «representaciones sociales» que adquieren estatus de realidad y dan carta de naturaleza a estas cualidades que quedan adhosadas al conjunto de individuos que viven o vivieron un determinado tiempo histórico. Posiblemente por eso es que la investigación social, y en especial los estudios sobre fenómenos juveniles, hayan relegado el análisis generacional, porque tiende a «construir algunos estereotipos sobre la gente joven de determinada época, por ejemplo, la 'generación perdida' y 'generación X' (década de los noventa), 'generación escéptica' (finales de los noventa), 'generación de la red’ (principios siglo XXI) (Alpízar y Bernal, 2003:11).

Cualquier noción de generación incorpora —en alguno de sus niveles- un componente identitario. Las ideas más extendidas dicen que el sólo hecho de haber nacido en un mismo momento de la historia supone ya un sentimiento de identidad y pertenencia a un colectivo. Esa idea la expone Ortega y Gasset cuando plantea que la pertenencia a una generación impone a todos los contemporáneos una forma «espontánea» de pensamiento que sienten íntimamente suya. Para Feixa, la identidad de una generación es un fenómeno relevante: es el gran factor estructurador de las culturas juveniles. «Las culturas juveniles más visibles — dice Feixa - tienen una clara identidad generacional, que sintetiza de manera espectacular el contexto histórico que las vio nacer» (Feixa, 1999:89). La misma idea se sigue al leer un pasaje de un artículo que relata la deriva de quienes fueron jóvenes en la década de los ochenta y en el que se lee: «La generación de los ochenta, que tanto nos pertenece como nosotros a ella» (Padre Ramiro, 1999:30). Igual en otro artículo sobre la experiencia de quienes se criaron bajo dictadura: «Nací en 1973. Esto me hace formar parte de una generación especial; una generación que fue criada, aprendió a caminar, a multiplicar y a pololear durante el gobierno militar [...] Somos una generación que creció en un país donde el que se preocupaba del bien común era 'comunista', donde las personas que eran detenidas por 
carabineros 'en algo habrían estado metidas' y donde un señor de apellido Pinochet — al cual hoy se le atribuye la paternidad de nosotros-, era 'muy bueno porque nos cuidaba' o 'muy malo porque se llevó al tío Juan'. Aprendimos a vivir en un mundo claramente diferenciado: había 'gente buena' y 'gente mala' y no había más vuelta que darle» (Colchero, 1999:33).

Las palabras nuestra, somos, nos pertenece, traen la imagen de un «nosotros» que se siente por el sólo hecho de haber sido testigos de los mismos procesos históricos teniendo una misma edad. En cierto sentido, esta relación tiene algo de obviedad: el tiempo histórico es el medio desde donde cada individuo absorbe los recuerdos que van quedando en su memoria. Así se forma la conciencia, por los sucesivos y permanentes cruces entre el tiempo histórico y el estado de desarrollo biopsíquico de cada individuo. De ahí se entiende la permanente asociación entre generaciones y edad. Como plantea Augé, un antropólogo que estudia la vida en el Metro parisino, «las personas de la misma edad tienen necesariamente, si no recuerdos comunes, por lo menos recuerdos en común, los cuales, si difieren unos de los otros, distinguen aún más seguramente a quienes pueden referirse a los hechos recordados que a aquellos que, en el mejor de los casos, sólo tienen de ellos un conocimiento libresco» (Augé, citado en Feixa, 1999:88). El problema es que, si la experiencia directa permite conocer de primera fuente, ser testigo presencial de los hechos, saberlos porque se viven y no porque fueron contados, eso no significa que todos quienes fueron o son jóvenes a un mismo tiempo compartan necesariamente una misma «visión de mundo». De hecho, personas de una misma edad y que vivían en el mismo marco histórico-social estuvieron, por poner un ejemplo de la época que refieren los relatos citados, «a ambos lados de la barricada». Un carabinero y un poblador, si vivieron la misma realidad social e histórica, lo hicieron con sentidos absolutamente opuestos y eso a pesar de haber tenido la misma edad.

Esto se debe a que los acontecimientos históricos no se extienden parejamente por todo el espacio social; por el contrario, tienen efectos muy distintos según la estructura del campo y la posición en que se hallen los sujetos (cfr. Martín Criado, 1998:83-84). Pertenecer a una misma generación real, significa vivir los procesos históricos en una misma «etapa de la vida» biológica, pero eso no significa que se los observe desde una misma posición. Por el contrario, la forma en que se viven los procesos histórico-sociales depende de la situación en que se encuentra un grupo social en su particular relación con los procesos 
de un campo específico. Así se entiende que los acontecimientos que marcan los procesos históricos, incluso los más radicales y profundos, se expresen de distintas maneras dependiendo del espacio social. La represión que ejerció la dictadura militar chilena, por ejemplo, no tuvo la misma intensidad ni produjo los mismos efectos en sectores acomodados y en sectores «populares». Una diferencia análoga aparece si comparamos una gran ciudad con un pueblo rural alejado: lo que ocurrió durante la dictadura en Santiago, no fue lo mismo que en Hualañé o Cabreros. En este sentido, porque los procesos históricos llegan de manera distinta a cada espacio, las vivencias del «día a día» y los recuerdos que van quedando en la memoria de los sujetos que los habitan generan formas de conciencia posibles que son diferentes.

De todos modos, la situación de generación es sólo potencial y no asegura una identidad ideológica. La identidad en los modos de pensar y actuar no tiene que ver ni con la edad ni solamente con la situación socioespacial. Y es que vivir una misma situación no significa pertenecer a un grupo concreto: no implica relación, lazos, ni identidad subjetiva. Lo mismo ocurre con las condiciones de vida: no necesariamente se traducen en una forma compartida de interpretar la realidad. En una misma clase social o en un mismo espacio de residencia, pueden haber individuos que se identifican con formas de pensar distintas o incluso opuestas. Así se puede entender, por ejemplo, que un carabinero raso y un poblador de los años ochenta piensen distinto a pesar de que pudieron haber sido vecinos.

El punto es que las distintas situaciones que describe una generación pueden dar origen a distintos modos de interpretar su particular posición en el proceso histórico. Cada una de estas interpretaciones constituye una unidad de generación, una particular lectura y actitud frente a la situación que vive la generación como conjunto abstracto, como generación real. De ahí se entiende que sujetos que comparten una misma situación social y etaria, puedan unos adoptar, por ejemplo, posturas «conservadoras» y otros posturas más «liberales».

Esto tiene consecuencias importantes que alcanzan también al problema del tiempo. Si para la teoría de Ortega y Gasset este era un factor absoluto, si marcaba el fondo de todo pensamiento y acción, con esto se vuelve un factor relativo. Ya no marca del mismo modo a todos quienes nacieron en un mismo marco histórico-temporal: su influencia depende del contexto sociocultural y del grado de identidad que genere cada lectura de esa situación. 
La forma moderna de entender el problema del tiempo ha dado lugar a distintas interpretaciones teóricas sobre el proceso de cambio histórico. La teoría marxista lo entiende como el resultado de transformaciones económicas y sociales que están a nivel de las estructuras de producción: cuando cambian las estructuras productivas, cambian las relaciones de producción y la estructura de las sociedades. Así se mueve la historia y se pasa de un período a otro. El motor de todo es la «lucha de clases», que es la disputa por el control de los medios de producción. Por ella, los miembros de una clase imponen sus intereses y subordinan los de otras. De ahí que las clases sociales sean el sujeto histórico por excelencia: ellas son las agrupaciones sociales fundamentales, las únicas capaces de producir una ideología, generar identidad y promover acciones colectivas.

Otras teorías ubican los procesos de cambio histórico a nivel de los significados y prácticas compartidas por un grupo humano. Desde esta perspectiva, más que por transformaciones económico-estructurales, el cambio histórico pasaría por un cambio cultural. El supuesto es que cualquier Revolución, para ser más que una simple revuelta o una «rebelión social», debe llevar en su núcleo un nuevo modo de interpretar la realidad.

No se trata de rebelarse sólo contra los abusos sino contra los usos, dice Ortega y Gasset. «Las transformaciones de orden industrial o político son poco profundas: dependen de las ideas, de las preferencias morales y estéticas que tengan los contemporáneos. Pero, a su vez, ideología, gusto y moralidad no son más que consecuencias o especificaciones de la sensación radical ante la vida, de cómo se sienta la existencia en su integridad indiferenciada. Esta que llamaremos 'sensibilidad vital' es el fenómeno primario en historia y lo primero que habríamos de definir para comprender una época» (Ortega y Gasset, 1955:14). En este sentido, sólo planteándose cambios a ese nivel serían posibles las «verdaderas» transformaciones, las que cambian los aspectos profundos de la vida.

En esta perspectiva se ubican las teorías modernas de las generaciones. A todas las une el interés por explicar el paso de una a otra forma de entender y vivir el mundo. Como dice Ortega y Gasset, «las variaciones de la sensibilidad vital que son decisivas en historia se presentan bajo la forma de generación» (Ortega y Gasset, 1955:15). En este sentido, si por un lado los cambios históricos son más que sólo 
estructurales, por otro las generaciones, y no las clases sociales, son el sujeto que lo encarna. ${ }^{16}$

La relación entre generaciones y cultura que establecen estas teorías está siempre puesta en dos planos. Por un lado, las generaciones constituyen el vehículo básico para que los componentes de una cultura se transmitan. Como reconoce Mannheim, si una cultura se transmite en el tiempo, es precisamente porque se encarna en los cuerposmentes de los nuevos miembros, de las nuevas generaciones. Pero, por otro lado, las generaciones son también la forma en que se presenta el cambio cultural, el cuerpo en que se encarnan los cambios en las formas de ser y de pensar.

Sobre esta dialéctica entre generaciones y cultura, Ortega y Gasset plantea que «el pensamiento de una época puede adoptar ante lo que ha sido pensado en otras épocas dos actitudes contrapuestas —especialmente respecto del pasado inmediato, que es siempre el más eficiente y lleva en sí infartado, encapsulado todo el pretérito-. Hay, en efecto, épocas en las cuales el pensamiento se considera a sí mismo como desarrollo de ideas germinadas anteriormente, y épocas que sienten el inmediato pasado como algo que es urgente reformar desde su raíz» (Ortega y Gasset, 1955:12). No se trata, en todo caso, de que cada generación, cada nueva forma de «sensibilidad» irrumpa y rompa con toda la cultura acumulada. Si por un lado lo antes pensado representa «lo viejo», lo que hay que renovar, por el otro, es la base desde la cual se formula el nuevo pensamiento. «Las generaciones - dicenacen unas de otras, de suerte que se encuentra ya con las formas que a la existencia le ha dado la anterior. Para cada generación vivir es, pues, una faena en dos dimensiones: una de las cuales consiste en recibir lo vivido - ideas, valoraciones, instituciones, etc. - por la antecedente; la otra, dejar fluir su propia espontaneidad» (Ortega y Gasset, 1955:12).

La manera en que Ortega y Gasset explica este proceso de cambio cultural tiene ciertas peculiaridades. Antes que en el terreno amplio de «la cultura», de los «sentidos» y prácticas comunes que impregnan las formas de vida, la raíz del cambio cultural la ubica en el campo del conocimiento. Es el desarrollo de la filosofía y de las ciencias lo que hace germinar las fuerzas que impulsan los cambios de

16 Si consideramos que la redacción original del texto es en 1921, nos podemos dar cuenta que este planteamiento tiene consecuencias ideológicas, sobre todo si lo observamos a la luz de la época en que esta idea se formula: en medio de dos guerras mundiales y con la revolución bolchevique recién en sus primeros años. 
época. «De lo que hoy se empieza a pensar depende lo que mañana se vivirá en las plazuelas» (Ortega y Gasset, 1955:28-29); de ahí que si su teoría está atravesada por la figura de una «nueva generación», el verdadero agente de cambio histórico no es necesariamente «la juventud», sino más bien individuos específicos pertenecientes a la «élite intelectual» de una generación. ${ }^{17}$ Ellos son la «minoría selecta», los «elegidos», aquellos que traen el pensamiento de avanzada, las ideas del futuro. Son los «héroes» de la trama histórica, porque persisten a pesar de ser incomprendidos por sus contemporáneos, por los «vulgares» que forman la «masa anacrónica». ${ }^{18}$ De ahí que para Ortega y Gasset el verdadero problema de las generaciones sea «la distancia permanente entre los individuos selectos y los vulgares», factor que facilita o retarda — nunca impide - que la nueva forma de pensar, en principio de unos pocos, se vuelva común, característica de una época. ${ }^{19}$

El análisis que realiza Mannheim del proceso de cambio histórico-cultural es algo más complejo y explica con mayor detalle la función de las generaciones en el proceso de cambio de las mentalidades. Mannheim comparte la idea de que cada nuevo miembro de un grupo humano nace y crece en un marco definido históricamente. En cada fase de su desarrollo físico-psíquico, el individuo va tomando contacto con la realidad y con la cultura en que está inmerso y en ese contacto permanente, las experiencias vividas van quedando impresas en su

17 Con esto Ortega y Gasset llega a un problema importante para su época: el rol de los intelectuales en el proceso de transformación social. Lo particular es que, mientras para la izquierda los intelectuales estaban al servicio de la revolución socialista, de la «clase obrera», para él están al servicio de «la verdad», del conocimiento filosófico-científico.

18 El tono elitista de la teoría de Ortega y Gasset es evidente. De hecho, como lo plantea en algún momento, la diferencia entre «minorías selectas» y «muchedumbre» o «vulgares» parece responder a una condición «natural» o sustantivo a toda forma de agrupación humana.

19 Los estudios literarios suelen tomar prestada esta perspectiva teórica para aplicarla a su campo de estudio. La idea de fondo es que el conjunto de escritores que nacen y viven a un mismo tiempo, enfrenta una particular realidad histórica que les exige buscar la fórmulas estéticas que alcancen para dar cuenta de la realidad vivida y representar el «espíritu» de su tiempo. Como por lo general son todos buenos lectores, al buscar esas fórmulas inevitablemente lo hacen en relación a toda la literatura acumulada. Así, en esta dialéctica, la nueva generación desarrolla nuevas formas expresivas, sea a través de rupturas estéticas radicales, la formación de movimientos literarios, o un diálogo con las anteriores generaciones de escritores. 
memoria y su conciencia se estratifica. La idea de Mannheim, que es corroborada por diversas teorías psicológicas, es que las experiencias de la infancia forman las capas primeras de la consciencia y permanecen como las bases desde las cuales cada sujeto interpretará en adelante su realidad. En ellas se encuentran las partes más sólidas de la mentalidad de un sujeto, las que no cambian a pesar que varíen las situaciones de la vida misma.

Ahora bien, la cultura no es estática y va cambiando conforme a los procesos histórico-sociales. Cada individuo, en cada etapa de su vida, inevitablemente toma contacto sólo con una etapa del proceso histórico. El hecho biológico de nacer en una determinada etapa histórica, determina así el contacto con un estadio particular de una cultura. De ahí que mediante este proceso cognitivo se vayan generando formas de interpretar la realidad que introducen cambios a los patrones culturales existentes.

En el esquema que elabora Mannheim, la etapa de la juventud sí que tiene una importancia decisiva. La idea de fondo es que el modo en que se experimenta el tiempo histórico cristaliza como una forma «natural» de pensamiento que, al llegar a la juventud, alcanza una estructura definida. Una vez estable en sus componentes más básicos, esa forma de conciencia que se venía gestando desde las etapas primeras de la infancia, termina por incorporar como natural su particular interpretación de la cultura. El informe del PNUD arroja algunas luces sobre la forma actual de este complejo cruce de factores cuando señala, por ejemplo, que los jóvenes de hoy «no manifiestan temor o perplejidad frente a una sociedad en veloz transformación, llena de exigencias inéditas y de señales confusas. Para ellos ya es normal la inestabilidad social, familiar o laboral, la centralidad del consumo, la comunicación sin límites y la diversidad de estilos y opciones de vida, realidades que para otros grupos de edad representan un mundo nuevo que se percibe además como amenazante» (PNUD, 2003:20). La forma en que ven el mundo quienes hoy son jóvenes no es sino la forma de conciencia que expresa sus vivencias y que se plasma desde su particular posición en el curso de los procesos histórico-culturales. Lo mismo ocurre con su vida afectiva y sexual, con sus gustos y prácticas sociales cotidianas. «Para la juventud — señala el citado informe - es natural que el consumo sea una parte importante de la vida social. Por lo mismo, manejan una noción del espacio público distinta a la de sus padres. Pertenecer a un barrio y juntarse en la plaza parecen formas de encuentro un tanto obsoletas. En cambio, ir al mall para comprar y 
juntarse con otra gente resulta cada vez más cotidiano» (PNUD, 2003:20). En este sentido, cuando una generación se hace joven es el momento biográfico en que esa conciencia estratificada se puede llegar a materializar en formas concretas de pensamiento y, sobre todo, de prácticas cultural e históricamente relevantes. ${ }^{20}$

Otro campo donde se puede constatar esta situación es en el ámbito de la actitud política. Desde hace al menos diez años, la tendencia indica que cada vez es menor la proporción de jóvenes que se identifican con las lógicas de sentido con que opera el sistema político. Este es sin duda un fenómeno sociopolítico, pero también es un fenómeno generacional que se explica por la diferente socialización política de cada generación. Así lo plantean Baño y Faletto en un ensayo que analiza el fenómeno del apoliticismo. Para los autores, cada una de las distintas generaciones que identifican para su análisis «ha tenido un inicio de socialización política distinta y ha sido marcada por tales experiencias» de modo que, aunque todas se enfrenten conjuntamente a una misma situación histórico-social, «sus reacciones estarán influidas en gran medida por las diferencias que constituyen sus experiencias de socialización» (Baño y Faletto, 1992:7-8). A diferencia de generaciones anteriores que se formaron en épocas en que la participación política formal representaba un camino ampliamente aceptado para resolver la construcción de proyectos sociales, y «Lejos de la experiencia de politización de los 80», quienes hoy son jóvenes «visualizan la política en términos prácticos, más asociada con las posibilidades de logros individuales que con ideales o identificaciones colectivas» (INJUV, 2002:3).

La forma general en que se presenta la dinámica del cambio histórico-cultural en términos de generaciones, está representada en la oposición entre «viejos» y «jóvenes». Como plantea Bourdieu, el cambio representa una lucha, una «disputa de poder» entre las clases de edad que operan al interior de una sociedad o de cada grupo social. La manera más corriente de interpretar esta oposición ha sido el recurso a la figura del «conflicto intergeneracional», que reduce el problema a un asunto de base puramente psicológica, que sigue el curso de los «impulsos» que arrastran los cambios bioquímicos de la pubertad.

20 En efecto, muchos grupos o movimientos culturales más amplios que han propugnado cambios con sus particulares posturas frente a las pautas culturales de un momento histórico, han estado conformados principalmente por sujetos jóvenes, cosa particularmente verificable en el campo del arte. 
Si bien estos cambios son innegables, los alcances ideológicos que tiñen este modo de presentar el problema son evidentes. Al ser un conflicto «natural», significa que es «normal» que ocurra porque responde a una etapa obligada en el desarrollo de la psiquis humana. Al mismo tiempo, si sólo se trata de un «momento» en la vida, entonces el fondo del conflicto es pasajero y lo mejor sería «darle tiempo al tiempo» hasta que el individuo «madure» y «se le pase». En estos términos, todo se explicaría por procesos individuales y las diferencias se enmarcarían en tipos de relación específicos: padre/hijo, alumno/profesor.

La evidencia histórica y antropológica nos dice que nada fuerza a pensar que el conflicto entre las generaciones sea inevitable. De hecho, en las sociedades estáticas, la sucesión de generaciones es un proceso que sigue cursos históricamente estables que hacen del cambio histórico un proceso lento e imperceptible en la inmediatez. ${ }^{21}$ De todos modos, en caso de haber conflicto entre viejos y jóvenes, su explicación es irreductible al plano de los procesos puramente psicológicos. Lo psicológico no es nunca individual: siempre tiene un fondo histórico-social que lo impregna. El conflicto o, más bien, la diferencia, cuando emerge, lo hace por procesos de cambio social. Como dice Bourdieu, «en una sociedad estática, donde las condiciones materiales de existencia con que se encuentran los nuevos miembros son idénticas a las que se encontraron los viejos en su tiempo, no habría diferencias de generación: las diferencias entre 'jóvenes' y 'viejos' serían meras diferencias de 'clases de edad', es decir, de los roles asignados a cada uno. Si fueran eso, las generaciones no serían sino el modo en que se reproducen las estructuras sociales, las estructuras de poder. Pero cuando cambian las condiciones de reproducción de los grupos sociales y, por ende, las condiciones materiales y sociales de producción de nuevos miembros, es cuando se producen diferencias de generaciones: los nuevos miembros son generados de manera distinta» (Bourdieu, citado en Martín Criado, 2003b:4).

De todos modos, el conflicto generacional es una figura que representa procesos socioculturales más profundos. El supuesto básico

21 «A importância da aceleração da mudança social para a realização das potencialidades inerentes a uma situaçao de generaçao é demostrada claramente no fato de que comunidades que se transformam muito lentamente ou são em grande parte estáticas, como a campesinato, não apresentam esse fenômeno de novas unidades de geração claramente distintas de suas predecesoras [...] em tais comunidades, o ritmo é tão gradual que as novas gerações se desenvovem longe de suas predecessoras sem qualquer ruptura visível». Mannheim, 1982:93. 
es que los viejos representan «lo viejo», lo que «ya no es» o está «dejando de ser», precisamente por la acción de «los jóvenes», que son quienes traen «lo nuevo», las nuevas formas de ser, pensar y actuar. Por los intersticios de esta oposición se filtraría el nuevo aire que prepara el cambio de época. El informe del PNUD nos entrega antecedentes que grafican este cambio, cuando señala que «los jóvenes suelen manifestar mayor tolerancia y menor discriminación que los adultos mayores, lo que supone una buena noticia y un aporte para el desarrollo humano» (PNUD, 2003:30). Para Ortega y Gasset, el asunto pasa por la «misión» que el estadio histórico de una sociedad le atribuye a cada generación desde que aparece en escena. A cada una la podemos pensar como «un proyectil biológico lanzado al espacio en un instante preciso con una violencia y una dirección determinadas. De una y otra participan tanto sus elementos más valiosos como los más vulgares [...] Si cada generación consiste en una peculiar sensibilidad, en un repertorio orgánico de íntimas propensiones, quiere decirse que cada generación tiene su vocación propia, su histórica misión» (Ortega y Gasset, 1955:17-20). Dependerá de su ímpetu el llevarla o no a buen puerto, el desarrollar o no "esos gérmenes interiores» e «informar la existencia en torno con el módulo de su espontaneidad» (ídem: 20). Lo importante de esto es que las nuevas «visiones de mundo» que declaran tener los jóvenes, se entiende son los gérmenes de una nueva forma de enfrentar la vida que se espera con el tiempo se convierta en el «espíritu» de la época que recién asoma. «Con seguridad la vida adulta de estos jóvenes será más individualizada que la de sus padres» (ídem:20). Según Ortega y Gasset, observando las «sensaciones vitales» de las generaciones jóvenes se podría anticipar el carácter de las épocas venideras. De hecho, para él la esencia de la ciencia histórica es precisamente la capacidad de hacer predicciones, de "prever el sentido típico del próximo futuro, anticipar el perfil general de la época que sobreviene» (ídem:20).

Una idea parecida sobre este mismo fenómeno lo entrega Mannheim con su noción de entelequia de las generaciones. Según Mannheim, cada nueva situación de generación crea nuevos impulsos colectivos y principios formativos originales que se deben adecuar a su particular situación. En ese contexto emergen los nuevos estilos de generación, las nuevas unidades generacionales. En un principio esas nuevas formas pueden nacer de la producción intelectual o práctica de agrupaciones específicas, formadas por sujetos unidos por lazos tendidos por el contacto directo y que se reunen en torno a ideas y proyec- 
tos compartidos. Lo interesante es que cuando esas ideas interpretan la situación histórica y social de sujetos que no necesariamente pertenecen al circulo del grupo específico en que surgen, pueden llegar a configurar una «fuerza espiritual» que luego se expande hasta generar formas de identidad colectiva sin importar la existencia o no de relaciones presenciales.

Cuando las actitudes frente a la realidad histórica logran unir y generar identidad más allá de la participación en alguna agrupación específica, sus principios pueden ampliarse y volverse actitud compartida por quienes viven una misma situación de generación, por quienes ocupan una misma posición social, histórica y biográficamente definidas. Así pueden aparecer agrupaciones o incluso movimientos sociales más amplios que se vuelven históricamente relevantes y que están unidos por un fuerte componente generacional. ${ }^{22}$ Además, en la medida en que interpreten otras situaciones de generación contemporáneas, las ideas que en un principio identifican a una situación de generación específica pueden llegar a identificar a una generación real —el conjunto de sujetos que comparten edades cercanas- o incluso a miembros de generaciones anteriores o posteriores que no lograron cristalizar las suyas propias. ${ }^{23}$

Sin embargo, a diferencia de Ortega y Gasset, Mannheim plantea que el paso de antiguas a nuevas formas de pensamiento no necesariamente tiene un sentido "progresista». El hecho que «las cosas cambien», no significa que «cambien para mejor». Como lo plantea Mannheim, cada generación tenderá a «reflexionar» sobre aquellos aspectos de la realidad que le parezcan problemáticos. Para eso puede crear

22 En la década de los ochenta en Chile se trabajó el concepto de movimiento juvenil-popular. La idea era analizar las posibilidades que los distintos tipos de agrupación juvenil convergieran en la formación de un movimiento generacional amplio que actuara políticamente y se convirtiera en el sujeto histórico capaz de generar el cambio de régimen político. Al final, se terminó constatando la fragmentación de sentidos que separaba a las distintas formas de ser joven de aquella época y que terminó por dificultar la conformación de este movimiento generacional.

23 El apolíticismo que se viene verificando con cada estudio sobre la juventud desde inicios de los 90, es un ejemplo de cómo las actitudes se pueden hacer extensivas y transmitir e, incluso, hacer más profundas al pasar de una generación a otra. Si revisamos los datos podremos reconocer esta tendencia. En 1997, el $52.4 \%$ de los jóvenes entre 20 y 24 años estaban inscritos en los registros electorales, mientras el año 2000 lo estaba el 29.8\%. La misma tendencia se observa para la siguiente cohorte: de un $77.4 \%$ que había inscritos en 1997 , se baja a un 59.4\% (Cfr. INJUV, 2002:83). 
crear nuevas formas o tomar elementos del pasado y adaptarlos a su particular situación histórica. En estos términos, el paso de una generación a otra sólo da cuenta de los movimientos que ocurren en el ámbito de las ideas, y nada más remite a las variaciones temporales en las formas de producir a los nuevos miembros de un grupo social. Como señala Bourdieu, estas variaciones, cuando se producen, siguen el curso de variación en las condiciones de existencia de cada grupo social específico. «Una clase o una fracción de clase - dice Bourdieu- está en decadencia, y por consiguiente orientada hacia el pasado, cuando no está en condiciones de reproducirse con todas sus propiedades de condición y de posición, y cuando, para reproducir su capital global y mantener su posición en el espacio social (la de su familia de origen o su posición presente), sus miembros más jóvenes, en una proporción importante, tienen que realizar por lo menos una reconversión de su capital, que se acompaña con un cambio de condición, marcada por un desplazamiento horizontal en el espacio social: cuando, en otros términos, la reproducción de la posición de clase llega a ser imposible (desclasamiento) o no se cumple si no es mediante un cambio de fracción de clase (reconversión). En ese caso, la transformación del modo de generación social de los agentes determina la aparición de generaciones diferentes, cuyos conflictos no se reducen a aquello que normalmente se inscribe en los conflictos generacionales, puesto que tienen por principio la oposición entre los valores y los estilos de vida asociados al predominio en el patrimonio del capital económico o del capital cultural» (Bourdieu, citado en Martín Criado, 1998:82). De ahí la particular importancia que reviste la ampliación que ha experimentado la cobertura del sistema educacional. Este proceso estructural ha significado la incorporación al sistema de un contingente masivo de estudiantes proveniente de los estratos socioeconómicos más bajos y en la expansión territorial del sistema que se traduce, en último término, en la mayor incorporación de jóvenes que habitan zonas rurales. El impacto de este proceso es decisivo, pues introduce un factor que es determinante en el tipo de experiencia y en los cursos que sigue la «estratificación de la conciencia» de los sujetos pertenecientes a estos grupos sociales. En efecto, la gran mayoría de los miembros de sus anteriores generaciones alcanzaron niveles de educación bastante menores y en condiciones escasamente comparables con las actuales y eso, sin duda, constituye un proceso sociocultural que modifica los modos de generación de nuevos miembros en estos grupos sociales. 
De todo esto se desprende que no es la sucesión de generaciones lo que impone el ritmo al cambio histórico. Como plantea Mannheim, no es que los procesos sigan ritmos parejos de quince, treinta o más años, que es el tempo que Aristóteles, Ortega y Gasset y otros le han dado a la sucesión de generaciones. Por el contrario, los procesos históricos tienen su propio ritmo y dependen de muchos más factores que la sola aparición de nuevos miembros. ${ }^{24}$ Las generaciones son un factor constante, no dinámico: está siempre presente y es inevitable; por eso que la explicación del movimiento dependa más de una teoría del cambio histórico que incorpore, pero no que descanse en el fenómeno generacional.

\section{GENERACIONES Y PRODUCCIÓN DE JUVENTUDES}

La idea de las generaciones nos recuerda elementos que son claves para entender nuestra condición: que los humanos somos seres biológicos, que nacemos por un proceso biológico, que nuestro crecimiento es biológico, que pensamos porque poseemos una estructura biológica, que dejamos de existir sólo cuando dejamos de funcionar como seres biológicos $\mathrm{y}$, por último, que los fenómenos sociales y humanos se producen porque existen los seres humanos. De ahí la importancia de adoptar una perspectiva generacional para cualquier análisis de fenómenos sociales.

En el campo específico de los estudios de juventud, la incorporación de una perspectiva generacional es particularmente importante. Y es que cuando se reflexiona sobre fenómenos juveniles, inevitablemente se piensa sobre fenómenos generacionales. Aunque no siempre quede manifiesto, esta realidad es evidente. De hecho, los conceptos que los representan, dan cuenta de una realidad que es generacional. El concepto de tribu juvenil, por ejemplo, aparece precisamente por la presencia de un fenómeno generacional que se representa en esos términos.

Cualquier estudio sobre fenómenos juveniles y cualquier intento por teorizarlos debe tener en cuenta que está tratando con fenómenos generacionales. En este sentido, no se trata de conocimientos acabados que permitan encontrar leyes perennes sobre la condición juvenil. Por

24 «Quer um novo estilo de generação surja cada ano, cada trinta, cada cem anos, quer surja de modo totalmente ritmado, depende inteiramente de ação do proceso social e cultural». Mannheim, 1982:94. 
el contrario, si esta misma es una producción históricamente definida, las características (comportamientos, actitudes, formas de agrupación) que muestre en el presente son también expresiones de un momento, de una generación.

De todos modos, la juventud no es «la juventud», sino «las juventudes», y la juventud como generación no es una, sino varias generaciones. Las diferencias están dadas por la unión de la edad y los elementos socioculturales que marcan la biografía de los sujetos. En este sentido, el estudio de la juventud pensada como «generaciones de jóvenes» diferenciadas permite captar las distintas maneras en que se genera juventud en un tiempo histórico definido: en cómo ese tiempo y sus características determinan la producción de juventud. Por eso que la incorporación de una perspectiva generacional, para que sea efectiva, debe considerar la particular forma en que se producen los sujetos en cada grupo social y en relación a cada campo específico. Este ejercicio exige identificar los acontecimientos y procesos histórico-sociales que marcan la generación de nuevos miembros, de modo que se pueda comparar las distintas formas históricas del mismo proceso. Cuando se dice que la juventud ha cambiado, lo que se está diciendo es que las nuevas generaciónes de jóvenes son distintas. De ahí que su estudio sea siempre un ejercicio comparativo que exige comparar modos históricamente distintos de «ser joven» que deben dar cuenta de las particularidades para cada clase, para cada espacio y para cada género.

Lo importante es que el análisis comparativo entre las generaciones puede ser una entrada para el análisis histórico de una sociedad o de un grupo específico. Por eso cobra relevancia su incorporación al estudio de fenómenos juveniles, pues permite captar las ideas y las formas de enfrentar la vida que se adelantan para el futuro próximo. De todas maneras, el mayor problema que plantea este tipo de análisis es la definición de los límites entre una y otra generación: en base a qué criterios se definen sus límites o más allá de qué punto se puede decir que estamos frente a un conjunto humano con patrones subjetivos singulares. Cualquier intento por incorporar la perspectiva generacional debe resolver el problema de los límites entre las unidades generacionales. Como antes vimos, la tendencia ha sido establecer cortes en las edades aplicando un criterio ordinal para la construcción de «intervalos». Como alternativa, quedan dos caminos que pueden llegar a ser convergentes. El primero pasa por analizar la historia específica de un grupo social en sus distintas dimensiones, dar cuenta de los 
acontecimientos y procesos histórico-estructurales que lo definen y, a partir de ahí, identificar las «trayectorias típicas» que pueden alumbrar sobre los límites entre las viejas y las nuevas formas. El segundo pasa por diferenciar a las distintas unidades generacionales de acuerdo a las «ideas» que los unen; esto es, definir las «ideologías» que generan identidad, que agrupan y que establecen diferencias entre las distintas formas de «ser joven». Así, juntando ambos caminos y llevándolos a un campo específico — por ejemplo, la educación — se pueden comparar las distintas formas de «producir juventud» que coexisten en un mismo tiempo histórico y comparar esas formas con las pasadas, sea a nivel de un campo o bian a nivel de un grupo social específico.

VALPARAÍSO — VIÑA DEL MAR (CHILE), MAYO 2004

\section{BIBLIOGRAFÍA}

ALPÍZAR, LYDIA y MARINA BERNAL (2003): «La construcción social de las juventudes». Última Década N¹9. Viña del Mar: Ediciones CIDPA.

BAÑO, RODRIGO y ENZO FALETTO (1992): «El apoliticismo: el factor generacional». Serie Estudios Políticos No27. Santiago: FLACSO.

COLCHERO, FERnANDO (1999): «El país de los hijos de Pinochet». Revista Mensaje No479, Santiago.

CUADROS, RICARDO (2003): "Crítica literaria y fin de siglo: la novela chilena de Rodrigo Canovas». (www.critica.cl).

Duarte, Claudio (2002): «Mundos jóvenes, mundos adultos: lo generacional y la reconstrucción de los puentes rotos en el liceo. Una mirada desde la convivencia escolar». Última Década Nº16. Viña del Mar: Ediciones CIDPA.

FEIXA, CARLES (1999): De jóvenes, bandas y tribus. Barcelona: Editorial Ariel.

GRIMALDI, RALPH (1998): Matemáticas discreta y combinatoria. México: Adison Weslesy Longman.

INSTITUTO NACIONAL DE LA JUVENTUD (2002): Tercera encuesta nacional de juventud. Santiago: INJUV.

LAFOURCADE, ENRIQUE (1985): Antología del cuento chileno. Volumen I. Santiago: Editorial Alfa.

MANNHEIM, KARL (1982): O problema sociológico das generações. 
En M. FORACHI: Mannheim. São Paulo: Ática.

MARTÍN CRIADO, ENRIQUE (1998): Producir la Juventud. Madrid: Ediciones Istmo.

(2003a): «Generaciones/clases de edad».

(www.cholonautas.edu.pe).

(2003b): «Juventud». (www.nodulo.org).

ORTEGA Y GASSET, JosÉ (1955): El tema de nuestro tiempo. Madrid: Espasa-Calpe (octava edición).

PADRE RAMIRO (1999): «Voces de los 80». Revista Mensaje №479, Santiago.

PNUD (2003): Transformaciones culturales e identidad juvenil en Chile. Santiago: PNUD/INJUV.

SALEH, FERNANDO (2004): «La importancia de llamarse Chadwick». La Nación, Santiago, 28 de marzo. 